\title{
Diffuse Large B-Cell Lymphoma, Not Otherwise Specified Molecular Subtypes
}

National Cancer Institute

\section{Source}

National Cancer Institute. Diffuse Large B-Cell Lymphoma, Not Otherwise Specified

Molecular Subtypes. NCI Thesaurus. Code C148392.

Molecular subtyping of diffuse large B-cell lymphomas (DLBCL) based on structural genomic abnormalities and gene expression data obtained from biopsy samples. The molecular analysis revealed four subtypes of DLBCL (MCD, BN2, N1, and EZB) which have distinct genotypic, epigenetic, and clinical characteristics. (NEJM 2018; 378: 1396407) 